\title{
A cross-sectional study of screening for coronavirus disease 2019 (COVID-19) at the pediatric emergency department in Vilnius during the first wave of the pandemic
}

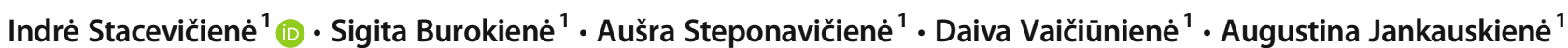

Received: 27 October 2020 / Revised: 11 February 2021 / Accepted: 17 February 2021 / Published online: 25 February 2021

(C) The Author(s), under exclusive licence to Springer-Verlag GmbH, DE part of Springer Nature 2021

\begin{abstract}
Screening for COVID-19 is based on clinical and epidemiological factors. Children infected with SARS-CoV-2 may have a few or many non-specific symptoms or may be asymptomatic. The aim of this study was to analyze clinical features and exposure to SARS-CoV-2 characteristics of children screened for COVID-19 at the pediatric emergency department in Vilnius during the first 3 months (March-May) of the COVID-19 pandemic in Lithuania. SARS-CoV-2 PCR was positive for $0.6 \%(8 / 1348)$ of all screened children and for $0.9 \%$ (7/811) of symptomatic patients, more among children with fever and cough $(2.6 \%, 4 / 154)$. There were also COVID-19 cases among children without cough but with other respiratory symptoms $(0.5 \%, 2 / 409)$ or gastrointestinal symptoms $(1.2 \%, 3 / 257)$. Only one child with positive SARS-CoV-2 did not meet COVID-19 clinical criteria - he presented with vomiting and dehydration only. All COVID19 cases $(n=8)$ had a contact with a confirmed COVID-19 family member. There were no COVID-19 cases among children without known exposure to SARS-CoV-2 or among asymptomatic children.

Conclusion: Screening for COVID-19 in children is exceptionally challenging due to the diverse and non-specific symptoms of infection they present. Testing strategies should not only focus on the typical COVID-19 symptoms of fever or cough, but also include other symptoms, especially gastrointestinal symptoms, which are also important. The greatest attention should be paid to known exposure to SARS-CoV-2, especially in family clusters. Screening of asymptomatic children with no known exposure should be weighed for medical necessity and cost-effectiveness.
\end{abstract}

What is Known:

- Diagnosis of COVID-19 in children is challenging because the disease does not always manifest with typical symptoms.

What is New:

- Children in our study who did not have symptoms of acute infection and contact with another person infected with COVID-19 were not diagnosed with COVID-19, so the benefit of PCR testing is questionable. Such testing may only be useful for infection control purposes, and to limit intra-hospital transmission.

Keywords COVID-19 $\cdot$ PCR $\cdot$ Children $\cdot$ Screening $\cdot$ Pediatric emergency department

Communicated by Nicole Ritz

Indrè Stacevičienè

indre.staceviciene@mf.vu.lt

Sigita Burokienè

sigita.burokiene@mf.vu.lt

Aušra Steponavičienè

ausra.vaiciulenaite@santa.lt
Daiva Vaičiūnienè

daiva.vaiciuniene@santa.lt

Augustina Jankauskienè

augustina.jankauskiene@mf.vu.lt

1 Clinic of Children's Diseases, Institute of Clinical Medicine, Faculty of Medicine, Vilnius University, Vilnius, Lithuania 


\begin{tabular}{|c|c|}
\hline bbre & \\
\hline COVID-19 & Coronavirus disease 2019 \\
\hline PCR & Polymerase chain reaction \\
\hline PED & Pediatric emergency department \\
\hline SARS-CoV-2 & $\begin{array}{l}\text { Severe acute respiratory syndrome } \\
\text { coronavirus } 2\end{array}$ \\
\hline $\mathrm{HO}$ & World Health Organization \\
\hline
\end{tabular}

\section{Introduction}

Since initially identified in Wuhan, China, in December 2019, coronavirus disease 2019 (COVID-19), which is caused by severe acute respiratory syndrome coronavirus 2 (SARS$\mathrm{CoV}-2$ ), has rapidly spread all around the world and was declared a worldwide pandemic by WHO in March 2020 [1]. More than 8 million people were confirmed to have COVID19 and over 400,000 people have died from the novel coronavirus in less than 6 months [2].

Lithuania was also affected by this global virus spread. On February 28, the first case of COVID-19 was confirmed in a woman who arrived from Italy. On March 18, the first case of local transmission of the virus was confirmed. During three spring months, there were 1670 cases diagnosed with COVID-19, including 53 children. There were 70 deaths reported among adults and no deaths among children. Vilnius was a leading city in Lithuania's confirmed cases [3].

Screening for COVID-19 is based on clinical and epidemiological factors. Children infected with SARS-CoV-2 may have a few or many non-specific symptoms or may be asymptomatic $[4,5]$. Although severe cases of COVID-19, including fatal cases, have been reported, most children appear to have mild or moderate disease $[4,6]$. The symptoms of acute COVID-19 infection usually mimic other childhood illnesses, mostly respiratory or gastrointestinal infections. The lack of specificity of signs or symptoms makes screening for identification of SARS-CoV-2 in children particularly challenging. Our aim was to analyze clinical features and exposure to SARS-CoV-2 characteristics of children screened for COVID-19 at the pediatric emergency department in Vilnius.

\section{Materials and methods}

For this retrospective, single-center study, patients were recruited from March 1 to May 31, 2020, at Vilnius University Hospital Santaros Klinikos. The study was approved by the Vilnius Regional Biomedical Research Ethics Committee (No. 2020/8-1269-737). Children were screened for SARS$\mathrm{CoV}-2$ according to the recommendations of the Ministry of Health, which changed several times according to epidemiological situation of COVID-19 in the country (Table 1). At the beginning of March, children with flu-like symptoms were initially tested for influenza $\mathrm{A}$ and $\mathrm{B}$ viruses. If the tests were positive and children had no known exposure to SARS-CoV2 , testing for COVID-19 was not performed.

Those patients under 18 years who tested for COVID-19 at the pediatric emergency department (PED) were enrolled in the study. Nasopharyngeal swabs were taken and real-time reverse-transcriptase polymerase chain reaction (PCR) tests were performed for all enrolled patients. The test samples were taken by several trained doctors. Children were excluded if the test was done as a repeat for an already-diagnosed COVID-19 case.

We stratified the patients into four groups (A-D) according clinical symptoms and exposure to SARS-CoV-2 (Fig. 1). Testing of asymptomatic children (group B and D) was performed for epidemiological reasons (to control the spread of COVID-19 in the hospital as well as in the community). Testing of symptomatic children (group A and C) was performed for establishing etiology but mainly for epidemiological reasons as well. Basic characteristics, source of infection, clinical signs and symptoms, laboratory results, and outcome data were obtained from the patients' electronic medical records. COVID-19 was diagnosed by a positive PCR while other final diagnoses (for example, upper respiratory tract infection, and infectious gastroenteritis) were taken from routine notes without specified criteria.

\section{Statistical analysis}

Statistical analyses were performed with IBM SPSS statistical software version 22. Categorical data were presented as frequencies and percentages, and analyzed using Pearson's chisquare or Fisher's exact test where appropriate. For continuous data, medians/interquartile range (IQR) and ranges were calculated. Likelihood ratios (LRs) were calculated with 95\% confidence intervals (CIs).

\section{Results}

During the first 3 months of the COVID-19 pandemic in Lithuania, 1348 children were screened for SARS-CoV-2 at the pediatric emergency department in Vilnius. The median age of the tested patients was 4.0 years (IQR 1.3-10.5, range $0-17$ years). The sex ratio was 1.24 males to every female. SARS-CoV-2 PCR tests were positive for $0.6 \%$ of children (8/1348): $0.8 \%$ of girls (5/603) and $0.4 \%$ of boys (3/745). The median age of the SARS-CoV-2 positive patients was 4.5 years (IQR 1.0-11.8, range $0-12$ years). COVID-19 was diagnosed for $0.8 \%$ of tested infants $(2 / 267), 0.3 \%$ of toddlers (1/320), $1.0 \%$ of preschool-age children (2/200), and $0.5 \%$ of school-aged children (3/561). 
Table 1 COVID-19 testing strategy during March-May 2020

\begin{tabular}{|c|c|c|}
\hline Date & $\begin{array}{l}\text { Daily new confirmed } \\
\text { COVID-19 cases in } \\
\text { Lithuania }^{\text {a }}\end{array}$ & Testing strategy in Lithuania \\
\hline Early March & $<10$ & $\begin{array}{l}\text { Patients with acute respiratory infection (sudden onset with } \\
\text { at least one of the following: fever, cough, shortness of } \\
\text { breath) } \\
\text { And one of the following: } \\
\text { - During the } 14 \text { days prior to onset of symptoms were } \\
\text { traveling to areas with presumed ongoing community } \\
\text { transmission of COVID-19 (China, North Italy, Hong } \\
\text { Kong, Japan, Iran, South Korea, Singapore) } \\
\text { - Were in close contact with a confirmed or suspected case } \\
\text { of COVID-19 infection. }\end{array}$ \\
\hline Early April & $10-90$ & $\begin{array}{l}\text { Patients with acute respiratory infection (sudden onset with } \\
\text { at least one of the following: fever, cough, shortness of } \\
\text { breath) } \\
\text { And one of the following: } \\
\text { - During the } 14 \text { days prior to onset of symptoms were } \\
\text { traveling to areas with presumed ongoing community } \\
\text { transmission of COVID-19 (different countries) } \\
\text { - Were in close contact with a confirmed or suspected case } \\
\text { of COVID-19 infection } \\
\text { - No other reasons of onset symptoms } \\
\text { Any child who came with fever to pediatric emergency } \\
\text { department }\end{array}$ \\
\hline Early May & $3-35$ & $\begin{array}{l}\text { As above } \\
\text { Additional: } \\
\text { - Any child requiring hospital admission and his } \\
\text { representative, who stays in the hospital } \\
\text { - Follow-up on confirmed COVID-19 pediatric patients }\end{array}$ \\
\hline
\end{tabular}

${ }^{\text {a }}$ Official statistics portal. COVID-19 related population and business statistics, https://osp.stat.gov.lt/en

A majority of COVID-19 cases were diagnosed among children with known exposure to SARS-CoV-2 and with known COVID-19 symptoms (group A, Table 2). Only one child testing positive for SARS-CoV-2 (in group B) did not meet COVID-19 clinical criteria recommended by European Centre for Disease Prevention and Control (ECDC) - he presented with vomiting and dehydration only. There were no confirmed COVID-19 cases among children without known exposure to SARS-CoV-2 (groups C and D).

Distribution of groups A-D was calculated on a weekly basis, as shown in Fig. 2. Over time, total testing volumes increased significantly with a decrease of COVID-19 positive patients: during 9-15 calendar weeks five COVID-19 cases from 292 tested children were found, contrary to 16-22 calendar weeks, when 1056 children were tested and only three COVID-19 cases were found $(p=0.005)$. Fewer children with known exposure to SARS-CoV-2 were tested over time (78 vs 37 in group A and 15 vs 7 in group B during 9-15 vs 16-22 weeks, respectively) with a high increase of tested children without known exposure to SARS-CoV-2 (155 vs 541 in group $C$ and 44 vs 471 in group D during 9-15 vs 16-22 weeks, respectively).
More than half of tested patients $(811 / 1348,60.2 \%)$ had known COVID-19 symptoms: fever (785/811, 96.8\%), cough $(178 / 811,21.9 \%)$, or shortness of breath $(16 / 811,2.0 \%)$. SARS-CoV-2 PCR was positive for $0.9 \%$ (7/811) of symptomatic patients, more among children with fever and cough $(2.6 \%, 4 / 154)$. The symptom that increased the likelihood to have a positive SARS-CoV-2 PCR the most was cough (positive LR, 6.1 [95\% CI, 1.6-26.0], $p=0.015$ ). Nevertheless, COVID-19 was diagnosed among children without cough but with fever and other respiratory symptoms $(0.3 \%, 1 / 295)$ or with fever and gastrointestinal symptoms $(0.9 \%, 2 / 224)$. There were no COVID-19 patients among children with shortness of breath $(0 / 23)$, with the only symptom of fever $(0 / 24)$ or among those with cough but without fever (0/17). Only one child (patient 8 , Table 3 ) with symptoms inconsistent with COVID-19 clinical criteria had positive SARS-CoV-2 PCR. There were no COVID-19 cases among asymptomatic children.

During March and April, a majority of children with known COVID-19 symptoms were also tested for influenza A and B viruses: 82\% (83/101) and 80\% (265/332), respectively. In March, $9.6 \%$ (8/83) of tested symptomatic children 
Fig. 1 Stratification of enrolled children. The single asterisk indicates a history of travelling to affected areas during the last 2 weeks or a close contact with a confirmed or probable COVID-

19 case in the last 14 days, while the double asterisks mean a sudden onset of at least one of the following: cough, fever, shortness of breath

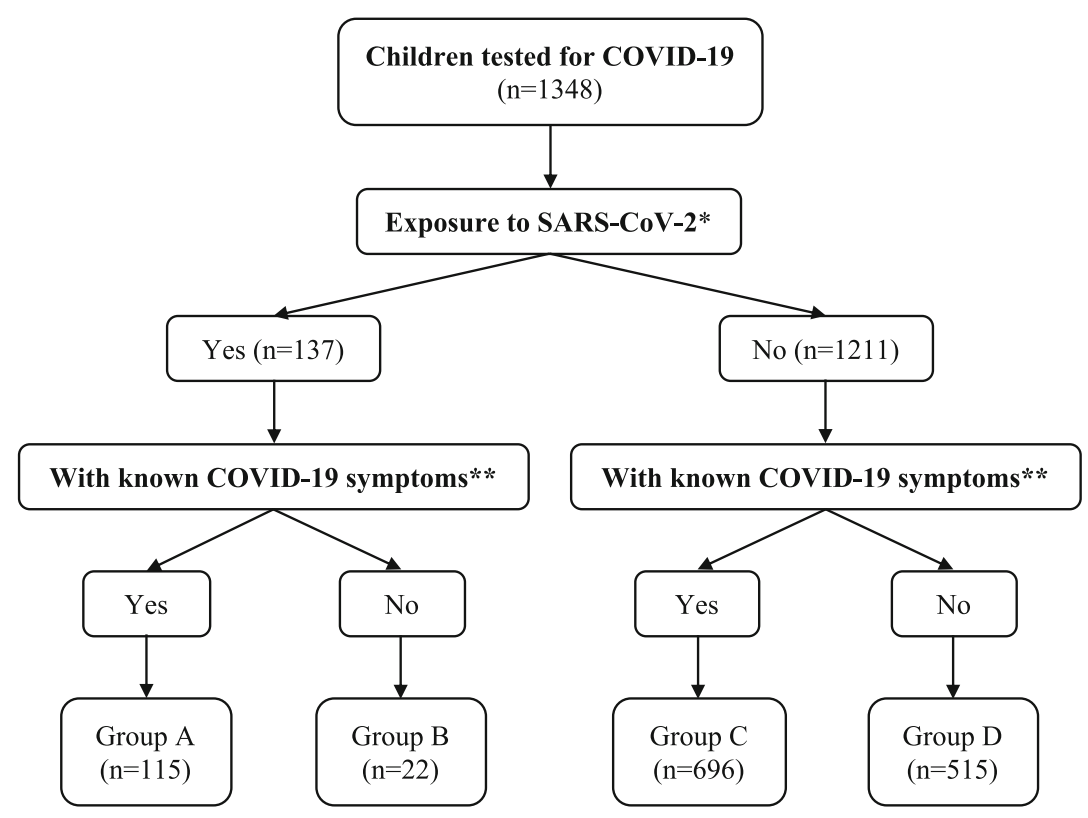

* a history of travelling to affected areas during the last two weeks or a close contact with a confirmed or probable COVID-19 case in the last 14 days

** a sudden onset of at least one of the following: cough, fever, shortness of breath

Table 2 Exposure and clinical characteristics of children in different groups (A-D)

\begin{tabular}{|c|c|c|c|c|}
\hline Characteristics & $\begin{array}{l}\text { Group A } \\
N=115\end{array}$ & $\begin{array}{l}\text { Group B } \\
N=22\end{array}$ & $\begin{array}{l}\text { Group C } \\
N=696\end{array}$ & $\begin{array}{l}\text { Group D } \\
N=515\end{array}$ \\
\hline Median age (IQR) & $3.0(1.2-9.2)$ & $6.0(2.3-10.4)$ & $2.3(1.0-7.5)$ & $7.4(2.8-12.7)$ \\
\hline Female (no. (\%)) & $59(51.3)$ & $7(31.8)$ & $318(45.7)$ & $219(42.5)$ \\
\hline \multicolumn{5}{|l|}{ Exposure to SARS-CoV-2 (no. (\%)) } \\
\hline A history of travel in affected areas & $34(29.6)$ & $10(45.5)$ & - & - \\
\hline Family cluster $^{\mathrm{b}}$ & $11(9.6)$ & $4(18.2)$ & - & - \\
\hline Contact with other ${ }^{\mathrm{c}}$ confirmed case & $6(5.2)$ & $1(4.5)$ & - & - \\
\hline Contact with other ${ }^{\mathrm{c}}$ suspected case & $64(55.7)$ & $7(31.8)$ & - & - \\
\hline \multicolumn{5}{|l|}{ Signs and symptoms (no. (\%)) } \\
\hline \multicolumn{5}{|l|}{ Fever $>37.3^{\circ} \mathrm{C}$ and: } \\
\hline - Cough \pm shortness of breath & 57 (49.6) & - & $107(15.4)$ & - \\
\hline - Rhinorrhea \pm pharyngeal erythema & $30(26.1)$ & - & $265(38.1)$ & - \\
\hline - Gastrointestinal symptoms ${ }^{\mathrm{d}}$ & $18(15.6)$ & - & $206(29.6)$ & - \\
\hline - Other symptoms & $5(4.3)$ & - & $82(11.8)$ & - \\
\hline Only fever $>37.3^{\circ} \mathrm{C}$ & $1(0.9)$ & - & $23(3.3)$ & - \\
\hline Cough without fever & $4(3.5)$ & - & $13(1.9)$ & - \\
\hline Positive COVID-19 PCR (no. (\%)) & $7(6.1)^{\mathrm{a}}$ & $1(4.5)$ & $0^{\mathrm{a}}$ & $0^{\mathrm{a}}$ \\
\hline
\end{tabular}

$I Q R$ interquartile range, $P C R$ polymerase chain reaction

${ }^{\text {a }}$ Significant differences were found between group A and group C $(p=0.000)$ and between group A and group D $(p=0.000)$

${ }^{\mathrm{b}}$ A contact with a suspected or confirmed family member

${ }^{\mathrm{c}}$ A contact with a suspected or confirmed case, except a family member

${ }^{\mathrm{d}}$ Gastrointestinal symptoms: vomiting, diarrhea, abdominal pain

${ }^{\mathrm{e}}$ Other symptoms: rash, headache, other pain, drowsiness 
Fig. 2 Distribution of A-D groups on a weekly basis. The asterisk indicates COVID-19 positive cases. Group A, cases with known exposure to SARSCoV-2 and with known COVID19 symptoms; group B, cases with known exposure to SARSCoV-2 but without known COVID-19 symptoms; group C, cases without known exposure to SARS-CoV-2 but with known COVID-19 symptoms; group D, cases without known exposure to SARS-CoV-2 and without known COVID-19 symptoms

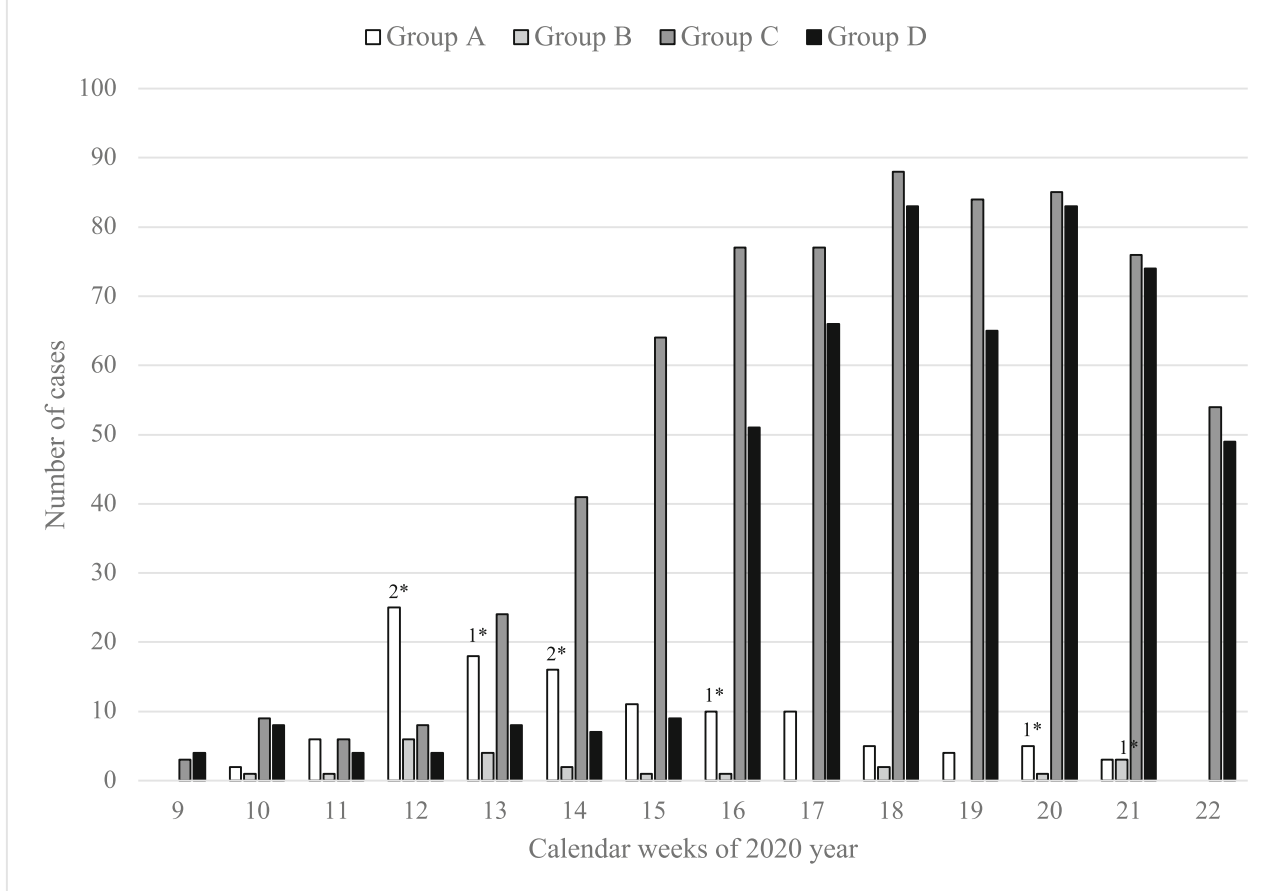

* COVID-19 positive cases

${ }^{a}$ Group A - cases with known exposure to SARS-CoV-2 and with known COVID-19 symptoms

Group B - cases with known exposure to SARS-CoV-2 but without known COVID-19 symptoms

Group C - cases without known exposure to SARS-CoV-2 but with known COVID-19 symptoms

Group D - cases without known exposure to SARS-CoV-2 and without known COVID-19 symptoms were diagnosed with flu: four children with influenza A, the other four with influenza B. Each of these had a negative SARS-CoV-2 PCR test. There were no influenza cases in April and May (Fig. 3). Upper respiratory tract infection was diagnosed for $14.8 \%$ (120/811) of symptomatic children; lower respiratory tract infection, $3.9 \%$ (32/811); infectious gastroenteritis and/or colitis, $9.6 \%$ (78/811); unspecified viral infection, $29.6 \%$ (240/811); unspecified bacterial infection, $7.8 \%$ (63/811).

Exposure to SARS-CoV-2 was known for 137 patients (10.2\%). Of these, COVID-19 was diagnosed for 5.8\% (8/137). Household transmission was the main source of exposure, with half of the children $(53.3 \%, 8 / 15)$ having a history of family cluster positive for SARS-CoV-2. A history of travel in affected areas was not as significant, with only $4.5 \%$ (2/44) of these patients positive for SARS-CoV-2.

All COVID-19 patients had clinical symptoms and COVID-19 positive family members (Table 3 ). The disease was mild to moderate. One boy was hospitalized because of suspected appendicitis; three children were admitted to the hospital for few days for observation. None was admitted to a pediatric intensive care unit. All COVID-19 patients had a good outcome. None had an underlying disease. No patients died.

The details of one case are worth noting because it illustrates something out of the ordinary. A 4-year-old boy (patient 7) came to the hospital following a 2-day history of fever (up to $39^{\circ} \mathrm{C}$ ), abdominal pain, and vomiting. He had no respiratory symptoms. Abdominal ultrasound suspected appendicitis and he underwent an appendectomy. The pathology confirmed acute appendicitis. COVID-19 was also diagnosed in this patient by a SARS-CoV-2 PCR, as his father and grandfather had confirmed COVID-19.

\section{Discussion}

To our knowledge, this is the first reported data on COVID-19 screening among children from Eastern Europe. We tested a high number of children in different age groups during a short period of time and found that SARS-CoV-2 PCR testing was positive for $0.6 \%$ of all screened children and for $0.9 \%$ of symptomatic patients, most frequently among children with fever and cough (2.6\%). Other countries reported different results. During the same period, 367 children were tested for SARS-CoV-2 at the pediatric emergency unit in Milan. The testing strategy was very similar and $33(9 \%)$ patients were diagnosed with COVID-19. Another study included 365 children screened for SARS-CoV-2 within 30 hospitals in Madrid during March with 41 patients (11.2\%) having positive PCR test results. Patients with a significant disease who were admitted, or likely to be admitted, or patients with signs or symptoms compatible with COVID-19 and the risk of complications due to baseline disease were included [7]. Similarly, a 
2142

Eur J Pediatr (2021) 180:2137-2145

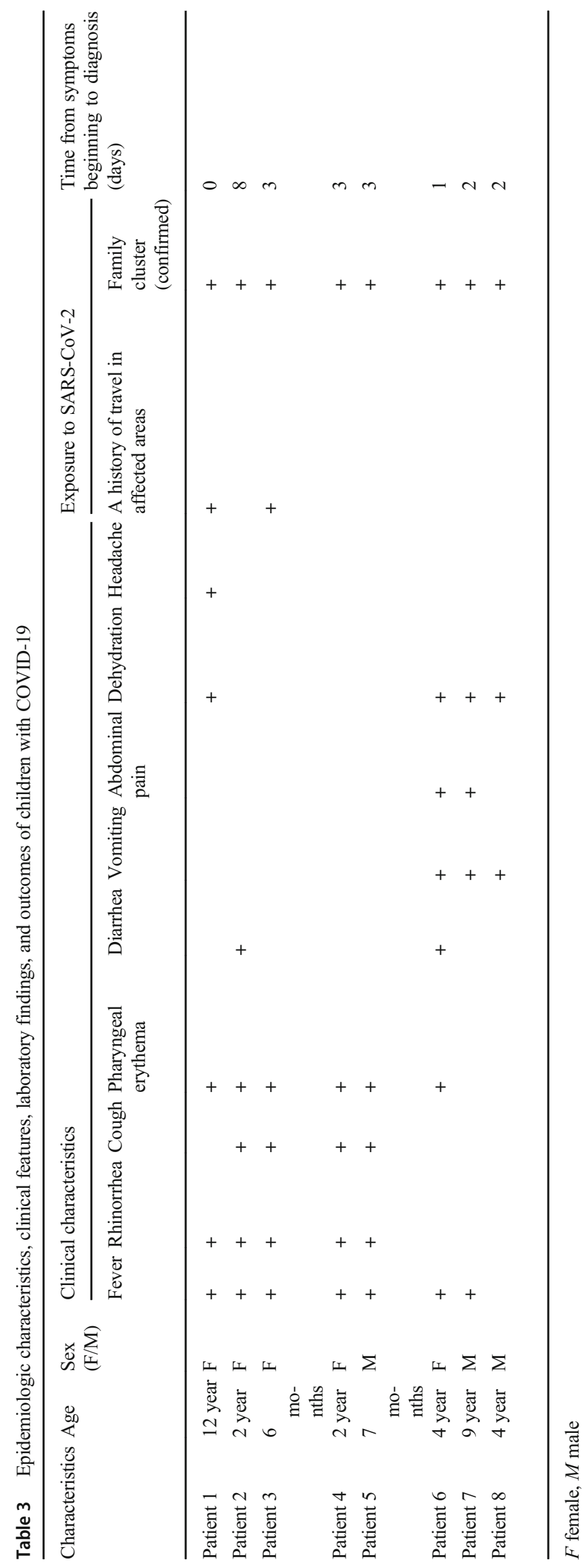

Springer 
Fig. 3 Children tested for influenza A and B viruses, March-May 2020

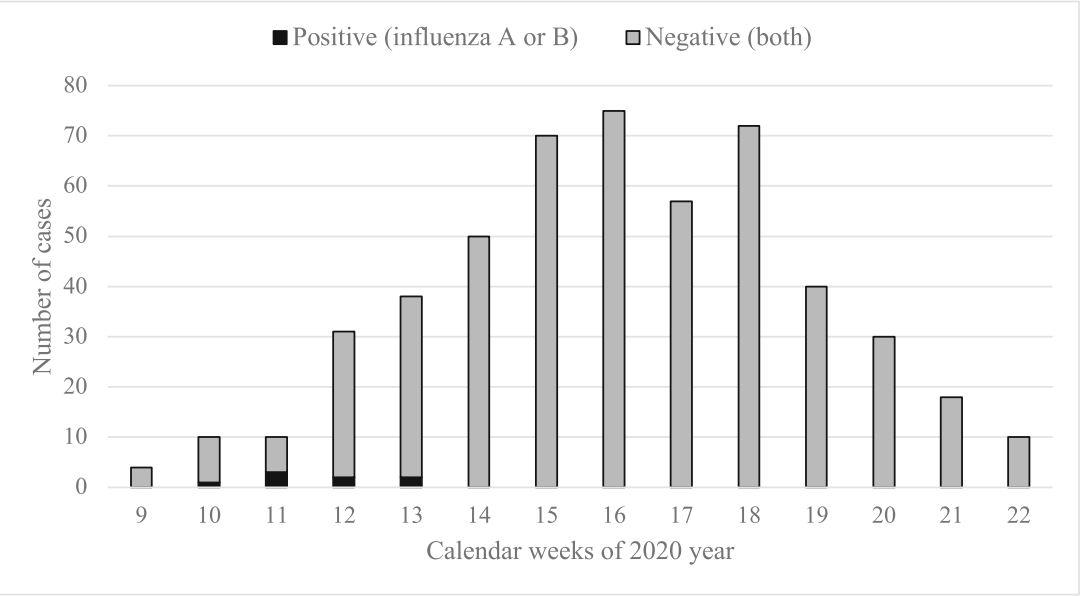

French prospective study was conducted in April and all hospitalized children $(n=438)$ were screened for COVID-19. SARS-CoV-2 PCR was positive for 22 patients (5.0\%) [8]. As we have evidence from Kohns Vasconcelos et al. [9] that testing strategies evolved very similarly across Europe, we can conclude that the differences between countries and our low numbers were determined by low circulation of COVID-19 in Lithuania due to early imposed major social contact restrictions during lockdown in the country and not by different testing methods, strategies, or patient approaches.

Children of all ages can get COVID-19, starting with neonates [10]. Our youngest patient was 6 months old and patients distributed in all age groups. In a multicenter European study, in which our hospital also took part in April 2020, about two-thirds of laboratory-confirmed SARS-CoV-2 patients were among participants younger than 12 months (29\%) and older than 10 years (34\%; up to 18 years) [5]. We did not see any age predominance in affected children, probably due to an overall low number of COVID-19 positive patients.

During the spring months of 2020, a high number of children presented to the PED with symptoms compatible with COVID-19. This new infection began at the end of the flu season in our country. At the beginning, a majority of children who were tested for SARS-CoV-2 were also tested for influenza A and B viruses. Flu was diagnosed only in March. Meanwhile, there were more COVID-19 cases from midMarch to mid-April. However, we found only a few cases of flu among children enrolled in this study. According to our COVID-19 testing strategy, a majority of influenza cases $(n=$ 84) in March were diagnosed among children with flu-like symptoms who did not have exposure to SARS-CoV-2; therefore, they were tested only for influenza viruses and were not included in our study. Unfortunately, this limits a comparison of COVID-19 and flu. We expect the coming season to be a considerable challenge, when more cases of both infections are expected at the same time.
The wide spectrum of COVID-19 symptoms complicates the selection of target groups for screening. We primarily differentiated between respiratory and gastrointestinal infections. We found more positive SARS-CoV-2 PCR results among children with typical COVID-19 symptoms (fever and cough), "a discreet respiratory illness cluster," as described by Swann et al. [11]. However, there were also COVID-19 cases among children without cough, but with other respiratory or gastrointestinal symptoms. Differently from Swann et al., we had children only with acute COVID-19 infection and had no patients with "mucocutaneous inflammation" or "neurological cluster" [11]. One child did not meet the COVID-19 clinical criteria recommended by European Centre for Disease Prevention and Control (ECDC) [12], presenting with vomiting and dehydration only. Increasingly, data suggest that gastrointestinal symptoms play an important role in children [13-15]. In our study, four of eight COVID-19 positive patients had gastrointestinal symptoms, and three with no respiratory symptoms. Only a few studies have reported SARSCoV-2 positive children with gastrointestinal symptoms and without respiratory symptoms $[15,16]$. Our results confirm that COVID-19 symptoms in children are diverse and nonspecific just like some other viral infections. Fortunately, testing is available for SARS-CoV-2. Otherwise, it would be almost impossible to diagnose COVID-19 in children based only on their symptoms. Confirming causative agent (SARS-CoV-2) is important for timely implementation of strict measures (such as self-isolation, contact isolation, and personal protection equipment for staff) to control the spread of COVID-19 in the hospital as well as in the community, especially to more vulnerable groups.

In addition, we reported an unusual case of acute appendicitis in a child with COVID-19. Tullie L. et al. reported eight children with COVID-19 presenting at a single center in the UK with symptoms of atypical appendicitis (fever, abdominal pain, diarrhea, and vomiting). All children had imaging confirming terminal ileitis and no surgical intervention was 
required [13]. In our case, it is hard to tell whether the patient's SARS-CoV-2 caused gastrointestinal symptoms or had an acute appendicitis concomitantly with asymptomatic COVID-19.

We also found that SARS-CoV-2 PCR results were negative for all the children who had no symptoms compatible with COVID-19 infection, otherwise we had no asymptomatic children at the start of the pandemic. This raises the question of cost-effectiveness in the need to test children without symptoms and without an epidemiologically significant anamnesis (a close contact with a confirmed case). However, according to other studies, $16-26 \%$ of children with COVID-19 were asymptomatic $[5,6]$. Our findings may be due to low virus circulation in the country, as the day care centers and schools were closed. Besides, our patients without known COVID-19 symptoms were children with cancer or other chronic disease who were hospitalized to continue the treatment. This group of patients carefully followed the rules and avoided any contact with sick persons, and this could have contributed to the results.

In our study, total testing volumes increased significantly over time with a high increase of tested children without known exposure to SARS-CoV-2 and we found no COVID19 cases in this group (both symptomatic and asymptomatic). All COVID-19 cases had a contact with a confirmed COVID19 family member. Thus, a history of exposure to SARS$\mathrm{CoV}-2$, especially in family clusters, is of great importance. A recent systematic review showed that a secondary attack ranges from 4.6 to $90.0 \%$, and a meta-analysis indicated the risk of household transmission to be about 10 times higher than that from other contacts [17].

Our study is limited in that it is retrospective and conducted in a single clinical center. However, the strategy of testing was defined by the Ministry of Health of Lithuania and was similar in all the settings countrywide. Although a high number of children were tested for SARS-CoV-2, only a few cases of COVID-19 were found. Due to the low number of positive COVID-19 cases, the resulting statistical analysis is limited. Additionally, it was difficult to identify significant relationships from the data and represent the population.

\section{Conclusion}

Screening for COVID-19 in children is exceptionally challenging due to the diverse and non-specific symptoms of infection they present. Testing strategies should not only focus on the typical COVID-19 symptoms of fever or cough, but include other symptoms, especially gastrointestinal symptoms, which are also important. Screening of asymptomatic children should be weighed for medical necessity and costeffectiveness. Systemic testing was only useful for limiting intra-hospital and intra-community transmission. The greatest attention should be paid to known exposure to SARS-CoV-2, especially in family clusters. In order to better understand the epidemiological situation among children in Lithuania, we plan to continue the study comparing data during different pandemic periods.

Acknowledgements Special thanks to the Vilnius University Hospital Santaros Clinics multidisciplinary medical staff for their contribution to the diagnostics and therapeutic management of the patients presented in this study. We also would like to thank Vilnius University Hospital Santaros Clinics biostatistics for their help in preparing materials, data collection, and data analysis.

Authors' contributions AJ conceived, initiated and designed the study, prepared all the study documents, contributed to data interpretation, and revised it critically. SB was a leading investigator, conceived, initiated and designed the study, prepared all the study documents, contributed to data interpretation, and revised it critically. DV conceived, initiated and designed the study, prepared all the study documents, contributed to data interpretation, and revised it critically. AS analyzed patient data and performed the calculations and statistical analysis. IS designed the study, prepared all the study documents, analyzed patient data, performed the calculations and statistical analysis, performed the literature review and took the lead in writing the manuscript and designing the figures. All authors have read and approved the manuscript in its current state.

Availability of data and materials Data generated during the study are subject to a data-sharing mandate and available in a public repository that does not issue datasets with DOIs.

Code availability Not applicable

\section{Declarations}

Ethics approval The study was approved by the Vilnius Regional Biomedical Research Ethics Committee (No. 2020/8-1269-737) in view of the retrospective nature of the study and all the procedures being performed were part of routine care.

Consent to participate Not applicable.

Consent for publication Not applicable

Conflict of interest The authors declare no competing interests.

\section{References}

1. World Health Organization (2020) Archived: WHO timeline COVID-19. https://www.who.int/news-room/detail/27-04-2020who-timeline\%2D\%2D-covid-19. Accessed September 5, 2020

2. European Centre for Disease Prevention and Control (2020) COVID-19 situation update worldwide, as of 5 September 2020. https://www.ecdc.europa.eu/en/geographical-distribution-2019ncov-cases. Accessed September 5, 2020

3. Registru centras (2020) Koronaviruso (COVID-19) Lietuvoje statistika. https://registrucentras.maps.arcgis.com/apps/ opsdashboard/index.html\#/becd01f2fade4149ba7a9e5baaddcd8d. Accessed May 31, 2020

4. Stokes EK, Zambrano LD, Anderson KN, Marder EP, Raz KM, El S, Tie Y, Fullerton KE (2020) Coronavirus disease 2019 case 
surveillance - United States, January 22-May 30, 2020. MMWR Morb Mortal Wkly Rep 69:759-765. https://doi.org/10.15585/ mmwr.mm6924e2

5. Götzinger F, Santiago-García B, Noguera-Julián A, Lanaspa M, Lancella L, Calò Carducci FI, Gabrovska N, Velizarova S, Prunk P, Osterman V, Krivec U, Lo Vecchio A, Shingadia D, SorianoArandes A, Melendo S, Lanari M, Pierantoni L, Wagner N, L'Huillier AG, Heininger U, Ritz N, Bandi S, Krajcar N, Roglić S, Santos M, Christiaens C, Creuven M, Buonsenso D, Welch SB, Bogyi M, Brinkmann F, Tebruegge M, Pfefferle J, Zacharasiewicz A, Berger A, Berger R, Strenger V, Kohlfürst DS, Zschocke A, Bernar B, Simma B, Haberlandt E, Thir C, Biebl A, vanden Driessche K, Boiy T, van Brusselen D, Bael A, Debulpaep S, Schelstraete P, Pavic I, Nygaard U, Glenthoej JP, Heilmann Jensen L, Lind I, Tistsenko M, Uustalu Ü, Buchtala L, Thee S, Kobbe R, Rau C, Schwerk N, Barker M, Tsolia M, Eleftheriou I, Gavin P, Kozdoba O, Zsigmond B, Valentini P, Ivaškeviciene I, Ivaškevicius R, Vilc V, Schölvinck E, Rojahn A, Smyrnaios A, Klingenberg C, Carvalho I, Ribeiro A, Starshinova A, Solovic I, Falcón L, Neth O, Minguell L, Bustillo M, Gutiérrez-Sánchez AM, Guarch Ibáñez B, Ripoll F, Soto B, Kötz K, Zimmermann P, Schmid H, Zucol F, Niederer A, Buettcher M, Cetin BS, Bilogortseva O, Chechenyeva V, Demirjian A, Shackley F, McFetridge L, Speirs L, Doherty C, Jones L, McMaster P, Murray C, Child F, Beuvink Y, Makwana N, Whittaker E, Williams A, Fidler K, Bernatoniene J, Song R, Oliver Z, Riordan A (2020) COVID-19 in children and adolescents in Europe: a multinational, multicentre cohort study. Lancet Child Adolesc Health 4: 653-661. https://doi.org/10.1016/S2352-4642(20)30177-2

6. Cui X, Zhao Z, Zhang T, Guo W, Guo W, Zheng J, Zhang J, Dong $\mathrm{C}, \mathrm{Na}$ R, Zheng R et al (2020) A systematic review and metaanalysis of children with coronavirus disease 2019 (COVID-19). J Med Virol 93:1057-1069. https://doi.org/10.1002/jmv.26398

7. Tagarro A, Epalza C, Santos M, Sanz-Santaeufemia FJ, Otheo E, Moraleda C, Calvo C (2020) Screening and severity of coronavirus disease 2019 (COVID-19) in children in Madrid, Spain. JAMA Pediatr. https://doi.org/10.1001/jamapediatrics.2020.1346

8. Poline J, Gaschignard J, Leblanc C, Madhi F, Foucaud E, Nattes E, Faye A, Bonacorsi S, Mariani P, Varon E et al (2020) Systematic SARS-CoV-2 screening at hospital admission in children: a French prospective multicenter study. Clin Infect Dis:ciaa1044. https://doi. org/10.1093/cid/ciaa1044/5876373

9. Kohns Vasconcelos M, Renk H, Popielska J, Nyirenda NM, Burokienė S, Gkentzi D, Gowin E, Donà D, Villanueva-Medina $\mathrm{S}$, Riordan A et al (2020) SARS-CoV-2 testing and infection control strategies in European paediatric emergency departments during the first wave of the pandemic. Eur J Pediatr 13:1-7. https://doi.org/10.1007/s00431-020-03843-w

10. Zeng L, Xia S, Yuan W, Yan K, Xiao F, Shao J, Zhou W (2020) Neonatal early-onset infection with SARS-CoV-2 in 33 neonates born to mothers with COVID-19 in Wuhan, China. JAMA Pediatr 174:722-725. https://doi.org/10.1001/jamapediatrics.2020.0878

11. Swann OV, Holden KA, Turtle L, Pollock L, Fairfield CJ, Drake TM, Seth S, Egan C, Hardwick HE, Halpin S et al (2020) Clinical characteristics of children and young people admitted to hospital with covid-19 in United Kingdom: prospective multicentre observational cohort study. BMJ 370:m3249. https://doi.org/10.1136/ bmj.m3249

12. European Centre for Disease Prevention and Control (2020) Testing strategies for SARS-CoV-2. https://www.ecdc.europa.eu/en/covid19/surveillance/testing-strategies. Accessed September 5, 2020

13. Tullie L, Ford K, Bisharat M, Watson T, Thakkar H, Mullassery D, Giuliani S, Blackburn S, Cross K, Coppi P et al (2020) Gastrointestinal features in children with COVID-19: an observation of varied presentation in eight children. Lancet Child Adolesc Health 4(7):e19-e20. https://doi.org/10.1016/S2352-4642(20)30165-6

14. Waterfield T, Watson C, Moore R, Ferris K, Tonry C, Watt A, McGinn C, Foster S, Evans J, Lyttle MD et al. (2020) Seroprevalence of SARS-CoV-2 antibodies in children: a prospective multicentre cohort study. Arch Dis Child 0:1-7. https://doi.org/ 10.1136/archdischild-2020-320558

15. Tian Y, Rong L, Nian W, He Y (2020) Review article: Gastrointestinal features in COVID-19 and the possibility of faecal transmission. Aliment Pharmacol Ther 51(9):843-851. https://doi. org/10.1111/apt.15731

16. Zachariah P, Johnson CL, Halabi KC, Ahn D, Sen AI, Fischer A, Banker SL, Giordano M, Manice CS, Diamond R et al (2020) Epidemiology, clinical features, and disease severity in patients with coronavirus disease 2019 (COVID-19) in a Children's Hospital in New York City, New York. JAMA Pediatr:e202430. https://doi.org/10.1001/jamapediatrics.2020.2430

17. Lei H, Xu X, Xiao S, Wu X, Shu Y (2020) Household transmission of COVID-19 - a systematic review and meta-analysis. J Infect S0163-4453(20):30571-30575. https://doi.org/10.1016/j.jinf.2020. 08.033

Publisher's note Springer Nature remains neutral with regard to jurisdictional claims in published maps and institutional affiliations. 